\title{
Left ventricular myocardial strain quantification with two- and three-dimensional cardiovascular magnetic resonance based tissue tracking
}

\author{
Yang-Yang $\mathrm{Qu}^{1,2} \wedge$, Jan Paul ${ }^{1}$, Hao $\mathrm{Li}^{1}$, Gen-Shan $\mathrm{Ma}^{2}$, Dominik Buckert ${ }^{1}$, Volker Rasche ${ }^{1}$ \\ ${ }^{1}$ Internal Medicine II, Ulm University Medical Center, Ulm, Germany; ${ }^{2}$ Department of Cardiology, Zhongda Hospital, School of Medicine, \\ Southeast University, Nanjing, China
}

Correspondence to: Volker Rasche; Dominik Buckert. Albert-Einstein-Allee 11, 89081, Ulm, Germany. Email: Volker.rasche@uni-ulm.de; Dominik.buckert@uniklinik-ulm.de.

Background: Cardiovascular magnetic resonance based tissue tracking (CMR-TT) was reported to provide detailed insight into left ventricular (LV) contractile function and deformation with both of two- and threedimensional (2/3D) algorithms. This study was designed to investigate the feasibility and reproducibility of these two techniques for measuring LV global and segmental strain, and establish gender- and age-related reference values of global multi-dimensional peak strains among large healthy population.

Methods: We retrospectively recruited 150 healthy volunteers (75 males/females) and divided them into three age groups $\left(\mathrm{G}_{20-40}, \mathrm{G}_{41-60}\right.$ and $\left.\mathrm{G}_{61-80}\right) . \mathrm{LV}$ global mean and peak strains as well as segmental strains in radial, circumferential and longitudinal directions were derived from post-hoc 2/3D CMR-TT analysis of standard steady-state free precession (SSFP) cine images acquired at $1.5 \mathrm{~T}$ field strength.

Results: Both 2D and 3D CMR-TT modalities enable the tracking of LV myocardial tissues and generate global and segmental strain data. By comparison, 3D CMR-TT was more feasible in measuring segmental deformation since it could generate values at all segments. The amplitudes of LV 3D global peak strain were the smallest among those of $2 / 3 \mathrm{D}$ corresponding global mean or peak strains except in the radial direction, and was highly correlated with 2D global mean strains (correlation coefficient $\mathrm{r}=0.71-0.90$ ), 2D global peak strains $(\mathrm{r}=0.75-0.89)$ and 3D global mean strains (all $\mathrm{r}=0.99)$. In healthy cohort, LV 3D global peak values were $44.4 \% \pm 13.0 \%$ for radial, $-17.0 \% \pm 2.7 \%$ for circumferential and $-15.4 \% \pm 2.3 \%$ for longitudinal strain. Females showed significantly larger amplitude of strains than males, especially in $\mathrm{G}_{61-80}(\mathrm{P}<0.05)$. The subjects in $\mathrm{G}_{61-80}$ showed larger amplitude of strains than the volunteers in younger groups. The intra- and inter-observer agreement of 2/3D CMR-TT analysis in evaluating LV myocardial global deformation was better than segmental measurement.

Conclusions: CMR-TT is a feasible and reproducible technique for assessing LV myocardial deformation, especially at the global level. The establishment of specific reference values of LV global and segmental systolic strains and the investigation of dimension-, gender- and age-related differences provide a fundamental insight into the features of LV contraction and works as an essential step in clinical routine.

Keywords: Cardiovascular magnetic resonance (CMR); tissue tracking; two- and three-dimension; strain; reference values

Submitted May 05, 2020. Accepted for publication Oct 27, 2020.

doi: 10.21037/qims-20-635

View this article at: http://dx.doi.org/10.21037/qims-20-635

\footnotetext{
^ ORCID: 0000-0003-1285-8584.
} 


\section{Introduction}

Cardiovascular magnetic resonance (CMR) is a powerful and efficient imaging modality, characterized by high spatial and temporal resolution, good soft tissue contrast and nonionizing radiation (1). It's extensively used in the quantitative measurement of left ventricular (LV) structure, function, tissue characteristics and perfusion in various cardiac pathologies (2,3). Additionally, CMR can derive deformation parameters including myocardial strain, which is defined as the percentage change of myocardial fiber length with respect to the diastolic phase in a certain direction. Strain is a three-dimensional (3D) tensor and thought to be a sensitive diagnostic index to detect subtle alternations in myocardial function before changes in ejection fraction (EF) (4-8).

Advanced CMR imaging techniques like tagging or tissue phase mapping have been introduced to measure strain. However, these techniques haven't entered into clinical utilization routinely because of the specific sequences, prolonged acquisition time or complex analysis $(4,9,10)$. Recently, with the rapid development of image post processing, CMR based tissue tracking (CMRTT) has emerged as a promising technique to evaluate myocardial deformation at both global and regional levels (10-14). The key strength of CMR-TT is the ability to generate mechanical parameters from standard steadystate free precession (SSFP) cine images, which allows post-hoc offline analysis. Two processing methods, namely two-dimensional (2D) and 3D CMR-TT modalities, have been introduced to derive the strain data. 2D CMR-TT is a conventional approach deriving strain values from the independent analysis of short- and long-axis cine images. In contrast, 3D CMR-TT considers the short- and long-axis data simultaneously for strain calculation. Previous studies found that 3D speckle tracking echocardiography (STE) is more accurate and reproducible than 2D STE in evaluating $\mathrm{LV}$ deformation due to independence of imaging plane and geometric assumptions $(6,15)$. However, only few studies compared the $\mathrm{LV}$ myocardial strains derived from $2 / 3 \mathrm{D}$ tracking techniques and established specific reference values for each modality.

In this contribution, we aim to: (I) compare LV global and segmental radial, circumferential and longitudinal systolic strains generated with 2D and 3D CMR-TT, and establish specific reference values for each modality; and (II) investigate gender- and age-related difference of 3D global peak strains followed by establishing specific reference values among 150 healthy volunteers.

\section{Methods}

\section{Study population}

A total of 150 healthy volunteers (75 males and 75 females) were recruited continuously and retrospectively analyzed. Inclusion criteria were: above 18 years of age; LVEF $\geq 55 \%$; no history of cardiovascular diseases or related risk factors (e.g., hypertension, coronary artery diseases, cardiac arrhythmia, dyslipidemia, diabetes mellitus or impaired glucose tolerance). Exclusion criteria were: symptoms of pulmonary dysfunction (e.g., chest tightness, pant and dyspnea), severe renal impairment (estimated glomerular filtration rate, eGFR $<30 \mathrm{~mL} / \mathrm{min}$ ), metallic transplant or foreign matter, claustrophobia and pregnancy. Healthy males and females were equally divided into three age groups as $\mathrm{G}_{20-40}$ (range $20-40$ years, $29.5 \pm 6.5$ years), $\mathrm{G}_{41-60}$ (range 41-60 years, 51.0 \pm 6.0 years), and $\mathrm{G}_{61-80}$ (range $61-80$ years, $69.1 \pm 5.9$ years). This study was approved by the local ethics committee. All subjects provided written informed consent.

\section{CMR protocol}

All participants underwent a conventional CMR examination on a clinical 1.5 Tesla whole body scanner (Achieva, Philips Healthcare, Best, The Netherlands). All data were acquired with a cardiac 32 -channel $(2 \times 16$-channels $)$ phased-array receive coil. A short-axis stack and long-axis cine images (2-, 3-, and 4-chamber view) covering the whole LV from base to apex were acquired with an electrocardiogram-gated breathhold SSFP sequence. Acquisition parameters were as: echo time $(\mathrm{TE})=1.5 \mathrm{~ms}$, repetition time $(\mathrm{TR})=3.0 \mathrm{~ms}$, flip angle $\alpha=55^{\circ}$, spatial resolution $\Delta \mathrm{r}=1.7 \mathrm{~mm} \times 1.7 \mathrm{~mm}$, field of view $(\mathrm{FOV})=360 \mathrm{~mm} \times 325 \mathrm{~mm}$, slice thickness $\mathrm{s}_{\mathrm{D}}=8$ $\mathrm{mm}$, no slice gap.

LV morphological and functional analysis was performed by two experienced readers with a standard software provided by the vendor $\left(\right.$ ViewForum $^{\circledR}$, Philips Healthcare, Best, The Netherlands). All LV functional parameters were normalized by the body surface area $\left[\mathrm{BSA}\left(\mathrm{m}^{2}\right)=0.007184 \times\right.$ height $^{0.725}$ $(\mathrm{cm}) \times$ weight $\left.^{0.425}(\mathrm{~kg})\right]$. Finally, images were exported to an external workstation for subsequent CMR-TT analysis.

\section{CMR-TT analysis}

CMR-TT was performed by an experienced observer 


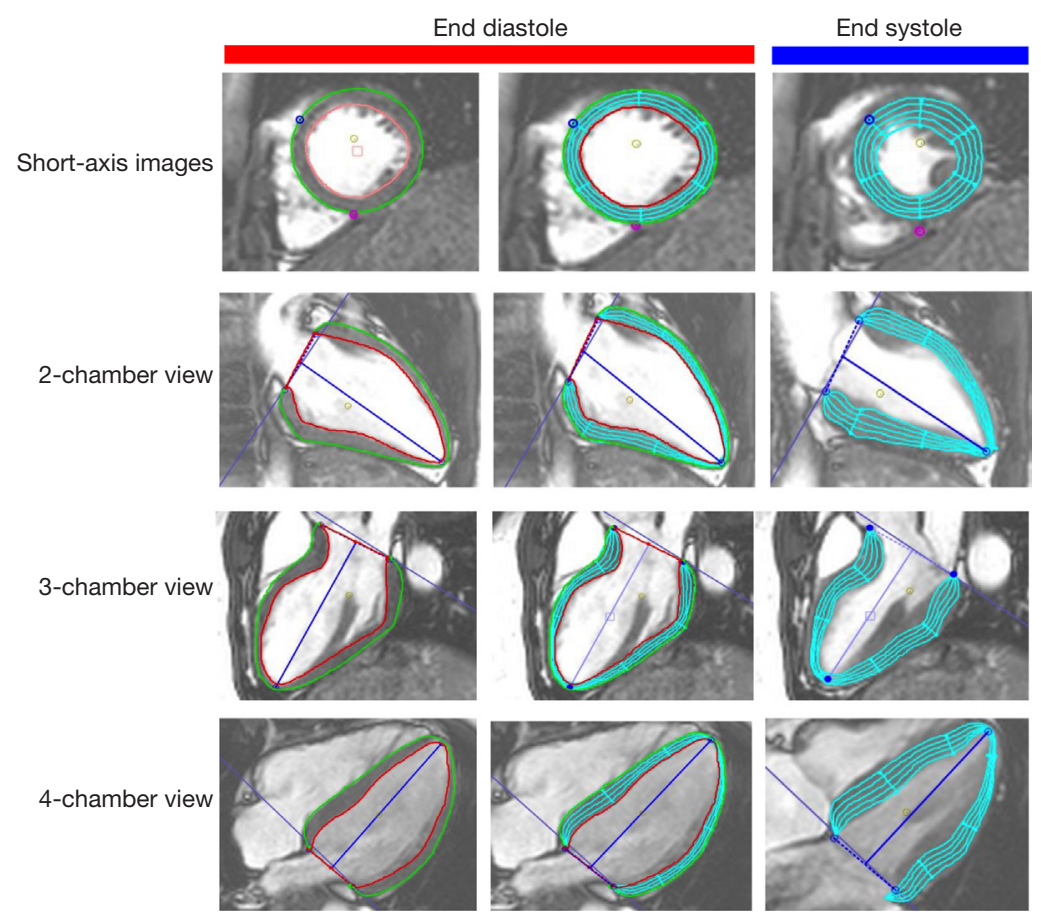

Figure 1 The operation of CMR-TT. Firstly, the LV endo- and epi-cardial contours (red and green lines) on LV short-axis cine images and long-axis 2-, 3-, and 4-chamber views were delineated at end-diastole. Secondly, blue and rose red reference points of interventricular septum at short-axis images as well as the blue $\mathrm{T}$ bar connecting the middle of mitral valve plane and apex were manually marked at the long-axis images to facilitate the division of myocardial segments and quantification of the LV length. Thirdly, automatic tracking of the myocardium was performed through all cardiac phases. The annular light blue mesh covering the myocardium and indicating the position and deformation of LV myocardial pixels could be divided into four or six segments by the vertical lines according to the AHA 17-segment model. CMR-TT, cardiovascular magnetic resonance based tissue tracking; LV, left ventricular.

using $\mathrm{CVI}^{42}$ (version 5.3.8, Circle, Calgary, Canada), which provided semi-automated delineation of $\mathrm{LV}$ endocardium and epicardium at end-diastolic phase on short- and longaxis images. Reference points were manually identified at the interventricular septum, mitral valve plane and apex to facilitate LV segmentation [according to AHA 17-segment model (16)]. The software automatically propagated the contours and tracked myocardial features phase by phase throughout whole cardiac cycle (Figure 1). The LV segmentation in each phase was checked and manually adjusted in case of failed boundary detection and/or segmental tracking.

The algorithms used in $\mathrm{CVI}^{42} 2 \mathrm{D}$ and $3 \mathrm{D}$ strain analysis have been discussed by Liu and $\mathrm{Hu}$ et al. $(17,18)$ before. Briefly, 2D CMR-TT determines the myocardial deformation by a set of reference points placed on the mid myocardial wall, which are tracked over the cardiac cycle in the short-axis or long-axis cine images. These reference points are generated during delineation of the
LV endo- and epi-cardial bounders at the end-diastolic phase. With the contraction and relaxation of myocardium, the positions of these reference points move and can be tracked by surrounding features in two directions, thus yield independent 2D motion fields for short- and longaxis data. 3D CMR-TT relies on a 3D deformation model generated by combining the 2D short- and long-axis image information into a single 3D motion field. Based on the motion fields, the myocardial strain is quantified either globally or segmentally in radial, circumferential and longitudinal directions.

In this study, 3D global and segmental radial, circumferential and longitudinal systolic peak strains (GRS, GCS, GLS and SRS, SCS, SLS) were derived by $\mathrm{CVI}^{42}$ directly. In the context of 2D CMR-TT, global and segmental peak CS and LS were derived from shortand long-axis cine images respectively, while peak RS was derived from both short- and long-axis cine images. The mean value was calculated for the following analysis. 
In some cases, 2D SRS could merely be obtained from short- or long-axis cine images, that extant value would be used for analysis. 2/3D global radial, circumferential and longitudinal systolic mean strains (MRS, MCS and MLS) were manually calculated by averaging 16 segmental systolic peak strain values.

\section{Intra- and inter-observer reproducibility}

The intra- and inter-observer reproducibility of LV global and segmental strains was assessed in 20 randomly selected subjects by two independently performed analyses or two observers. The intra- and inter-observer reproducibility of CMR-TT was quantified with the intra-class correlation coefficient (ICC) and coefficient of variation (CoV) (10).

\section{Statistical analysis}

Considering the limitation of segmental tracking, the number and percentage of successfully tracked segments, featured with available data, were recorded in order to evaluate the feasibility of both modalities. Continuous variables were described as mean \pm standard deviation $(M \pm$ SD). Normality of the data was tested using Shapiro-Wilk test. Gender-related differences were tested by Student's $t$-test or Mann-Whitney $\mathrm{U}$ test, as appropriate. Agerelated differences were assessed using analysis of variance (ANOVA) or Kruskal-Wallis test followed by Bonferroni correction, as applicable. Differences among four kinds of global strains $(2 / 3 \mathrm{D}$ global peak and mean strains) were assessed with related-samples Friedman's two-way analysis of variance by ranks, and Bonferroni correction was used to adjust the significance value. Pearson correlation coefficient or Spearman's rank correlation coefficient ( $r$ ) was used to test the collinearity of strains, as appropriate. All analyses were performed using IBM SPSS (version 24, IBM, Armonk, New York, USA). Statistical significance was set at $\mathrm{P}<0.05$ (two-tailed).

\section{Results}

\section{Baseline characteristics of the study participants}

The demographic, LV morphological and functional parameters of the investigated healthy volunteers are presented in Table 1. Average age resulted as $49.8 \pm 17.3$ years, with heart rate (HR) of $69.2 \pm 14.7$ beats per minute. Compared with females, males showed significantly larger
BSA, LV mass index (LVMI), LV mass normalized to enddiastolic volume (LVM/LVEDV), LV end-diastolic and end-systolic volume index (LVEDVI and LVESVI) and LV stroke volume index (LVSVI) (all $\mathrm{P}<0.05)$. No significant gender-related differences of age, HR, systolic and diastolic blood pressure (BP), cardiac index (CI) and LVEF were observed (all $\mathrm{P}>0.05$ ).

\section{$L V$ segmental strains derived from $2 D$ and $3 D C M R-T T$}

LV segmental radial, circumferential and longitudinal strains derived from 2D and 3D CMR-TT are presented in Tables 2-4 and Figure 2. The numbers of segments included in the analysis are defined as $\mathrm{N}_{2 \mathrm{D}}$ and $\mathrm{N}_{3 \mathrm{D}}$, respectively.

For radial strain analysis, $2.7 \%$ segments from shortand $3.6 \%$ segments from long-axis orientations had to be discarded in 2D CMR-TT, since these segments couldn't be tracked and generate data. However, after combing short- and long-axis data, 99.99\% segments were assigned with SRS. $97.3 \%$ and $96.4 \%$ segments were successfully tracked and generated SCS and SLS data with 2D CMRTT, respectively. Of note, the percentage of successfully tracked segments at basal inferior was merely $72.7 \%$ in the circumferential direction in the context of 2D CMR-TT. By comparison, no segments were excluded with 3D CMR-TT.

We found that 3D SRS was significantly larger than 2D SRS at basal and apical segments, and showed exactly contrary tendency at middle segments $(\mathrm{P}<0.05)$. The amplitudes of 3D SCS and SLS were smaller than 2D SCS and SLS at most segments from base to apex.

\section{$L V$ global strains derived from $2 D$ and $3 D C M R-T T$}

Normal values of $2 / 3 \mathrm{D}$ global mean and peak strains and the correlation between $3 \mathrm{D}$ global peak strains and the rest global strain parameters are presented in Table 5 and Figure 3. The 3D global peak values were $44.4 \% \pm 13.0 \%$ for radial, $-17.0 \% \pm 2.7 \%$ for circumferential and $-15.4 \% \pm 2.3 \%$ for longitudinal strains. The $2 \mathrm{D}$ and $3 \mathrm{D}$ data were similar for MRS $(46.8 \% \pm 9.5 \%$ vs. $48.0 \% \pm 13.5 \%$, adjusted $\mathrm{P}=0.644)$ and GRS $(41.7 \% \pm 9.5 \%$ vs. $44.4 \% \pm 13.0 \%$, adjusted $\mathrm{P}=0.644)$. The amplitudes of $3 \mathrm{D}$ global circumferential and longitudinal strains were significantly smaller than those of $2 \mathrm{D}$ corresponding strains (adjusted $\mathrm{P}<0.001$ ). For both 2D and 3D CMR-TT, the amplitudes of global peak strains were significantly lower than the calculated global mean strains (all adjusted $\mathrm{P}<0.05$ ). 
Table 1 Characteristics of the study participants

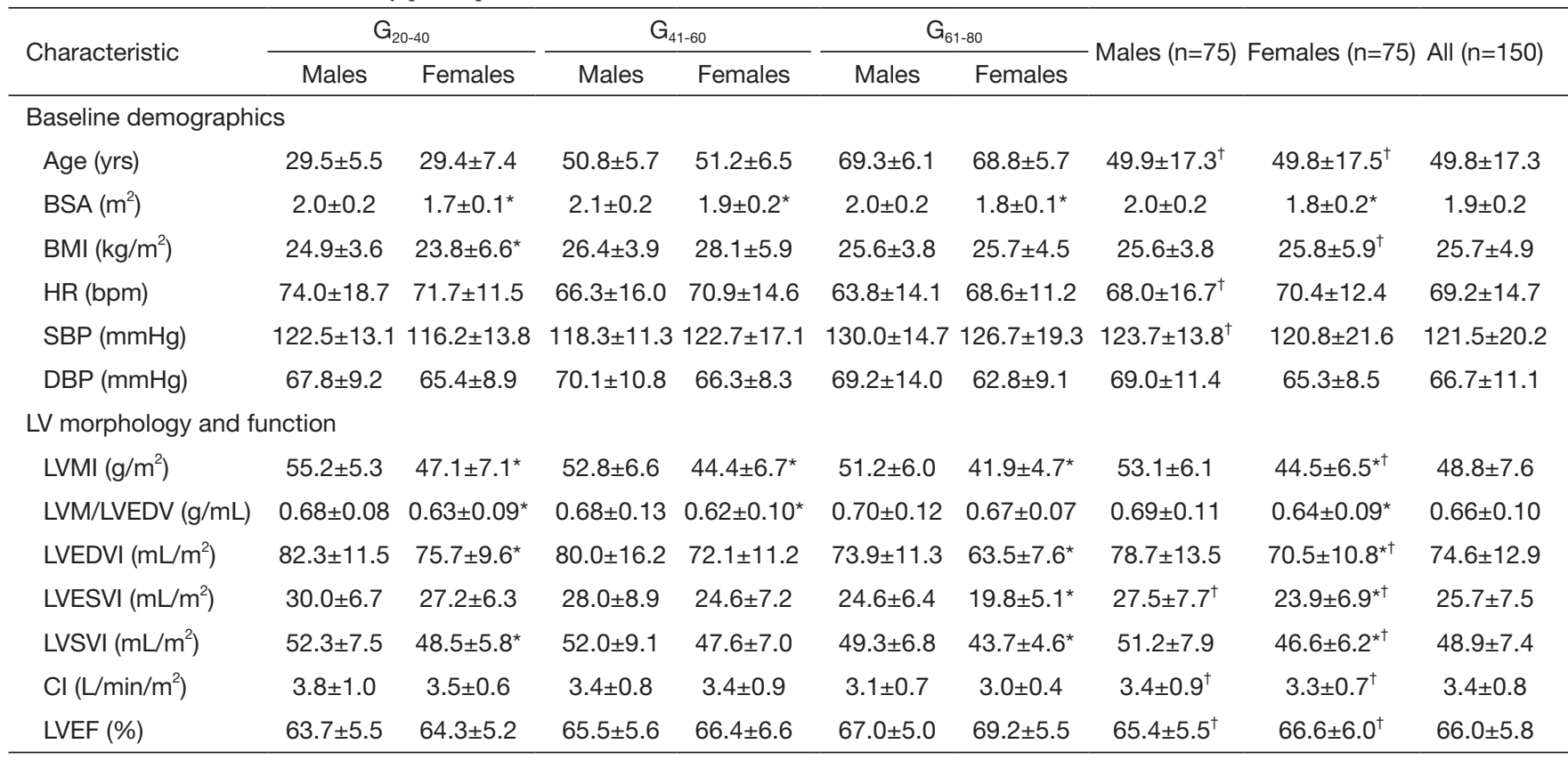

Results are reported as mean $\pm \mathrm{SD}$. ${ }^{*} \mathrm{P}<0.05$ : males vs. females. ${ }^{\dagger} \mathrm{P}<0.05$ : age-related difference among three age groups. $\mathrm{BSA}$, body surface area; BMI, body mass index; HR, heart rate; SBP, systolic blood pressure; DBP, diastolic blood pressure; LVMI, left ventricular mass index; LVM/LVEDV, left ventricular mass/left ventricular end-diastolic volume; LVEDVI, left ventricular end-diastolic volume index; LVESVI, left ventricular end-systolic volume index; LVSVI, left ventricular stroke volume index; CI, cardiac index; LVEF, left ventricular ejection fraction.

Table 2 Reference values of SRS measured with 2D and 3D CMR-TT

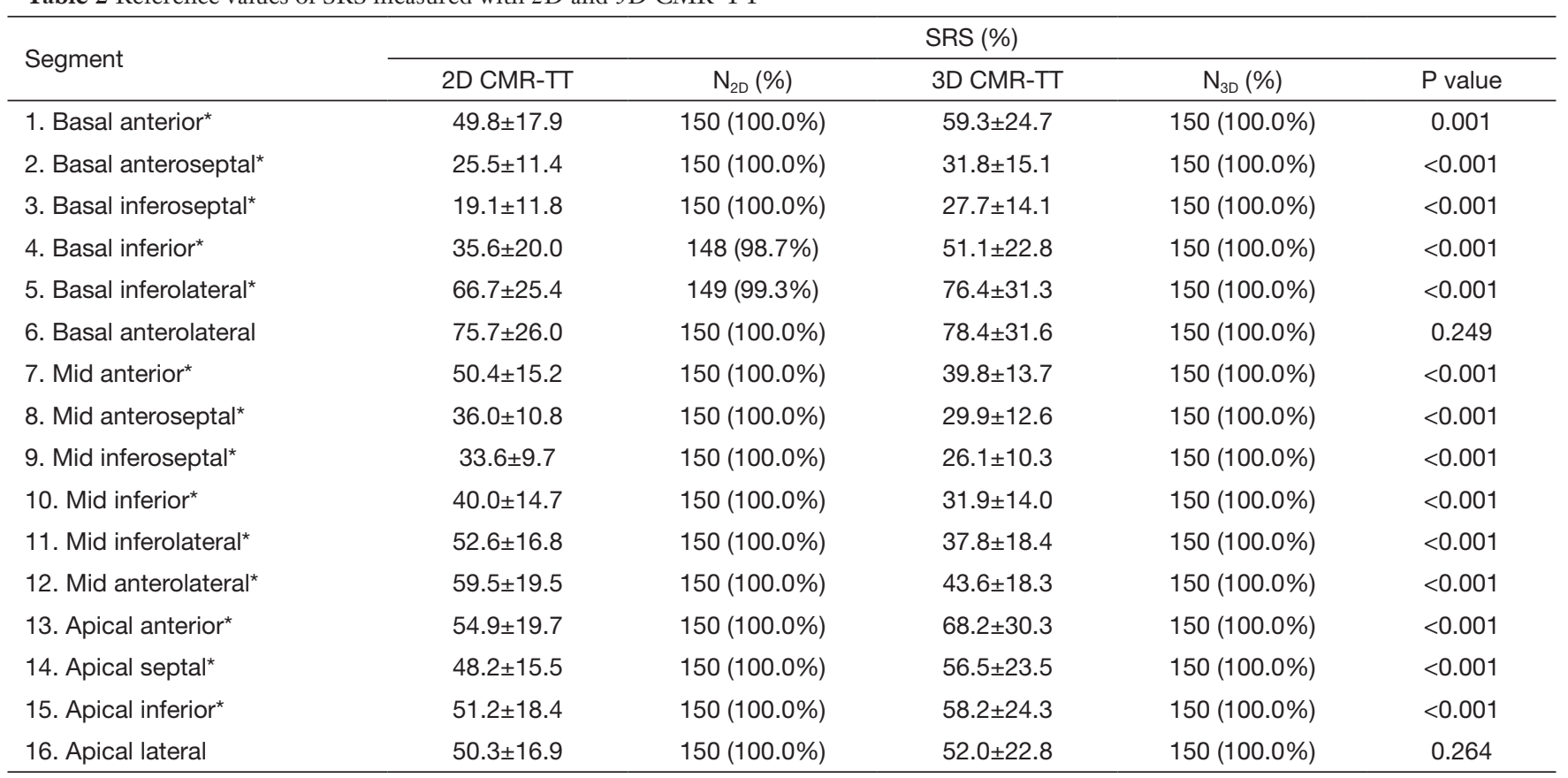

$\mathrm{N}(\%)$ means the number (fraction) of segments with available SRS. ${ }^{*} \mathrm{P}<0.05$. CMR-TT, cardiovascular magnetic resonance based tissue tracking; SRS, segmental radial peak strain. 
Table 3 Reference values of SCS measured with 2D and 3D CMR-TT

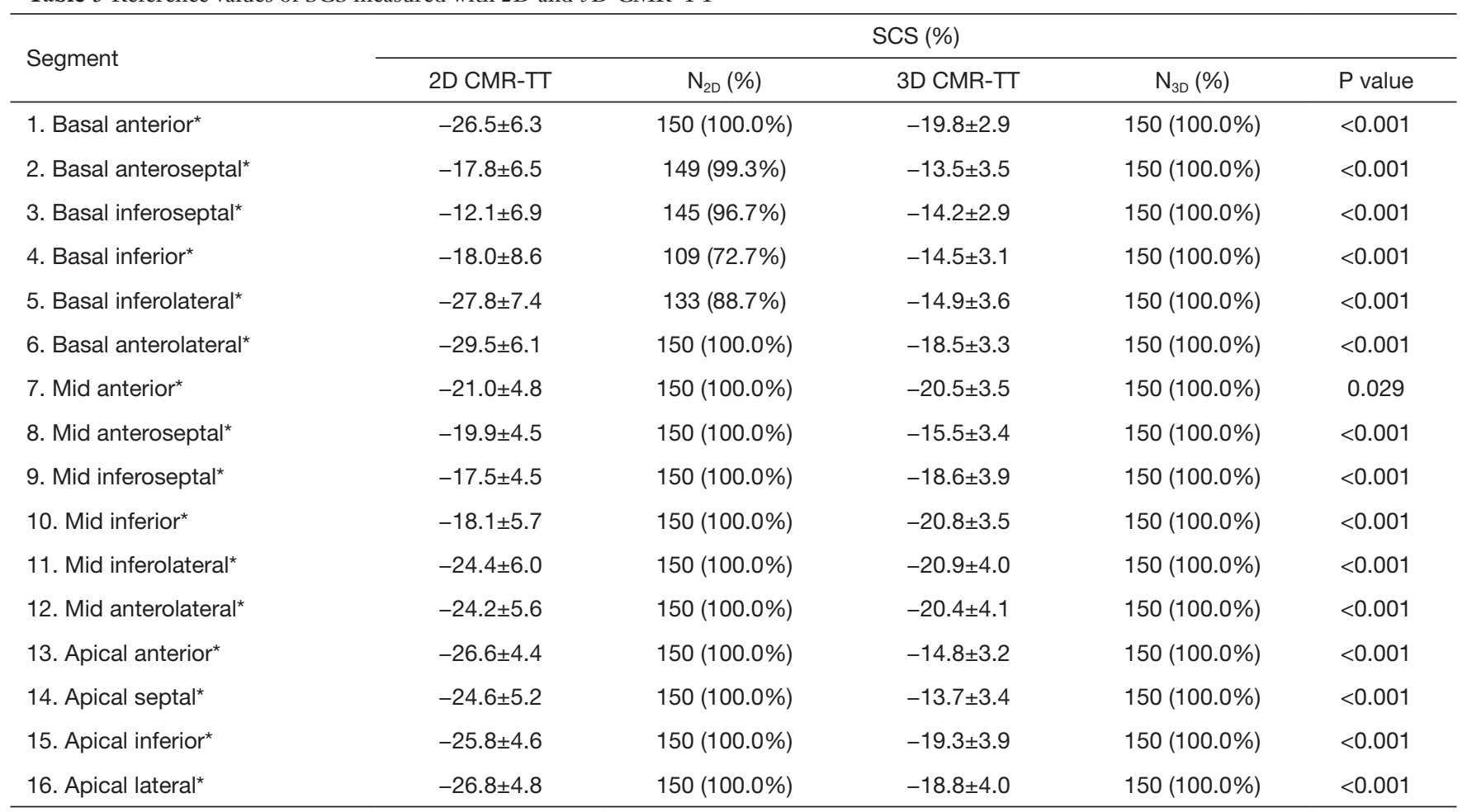

$\mathrm{N}(\%)$ means the number (fraction) of segments with available SCS. * $\mathrm{P}<0.05$. CMR-TT, cardiovascular magnetic resonance based tissue tracking; SCS, segmental circumferential peak strain.

Table 4 Reference values of SLS measured with 2D and 3D CMR-TT

\begin{tabular}{|c|c|c|c|c|c|}
\hline \multirow{2}{*}{ Segment } & \multicolumn{5}{|c|}{ SLS (\%) } \\
\hline & 2D CMR-TT & $\mathrm{N}_{2 \mathrm{D}}(\%)$ & 3D CMR-TT & $\mathrm{N}_{3 \mathrm{D}}(\%)$ & $P$ value \\
\hline 1. Basal anterior & $-17.8 \pm 6.0$ & $146(97.3 \%)$ & $-13.4 \pm 4.5$ & $150(100.0 \%)$ & $<0.001$ \\
\hline 3. Basal inferoseptal ${ }^{\star}$ & $-12.6 \pm 4.5$ & $143(95.3 \%)$ & $-10.5 \pm 3.3$ & $150(100.0 \%)$ & $<0.001$ \\
\hline 4. Basal inferior* & $-18.1 \pm 7.0$ & 139 (92.7\%) & $-9.3 \pm 4.3$ & $150(100.0 \%)$ & $<0.001$ \\
\hline 6. Basal anterolateral ${ }^{*}$ & $-26.3 \pm 7.0$ & $146(97.3 \%)$ & $-12.6 \pm 4.1$ & $150(100.0 \%)$ & $<0.001$ \\
\hline 7. Mid anterior* & $-26.2 \pm 4.7$ & 143 (95.3\%) & $-20.7 \pm 3.4$ & $150(100.0 \%)$ & $<0.001$ \\
\hline 8. Mid anteroseptal ${ }^{*}$ & $-19.7 \pm 3.9$ & $143(95.3 \%)$ & $-17.4 \pm 3.4$ & $150(100.0 \%)$ & $<0.001$ \\
\hline 9. Mid inferoseptal* & $-20.6 \pm 3.5$ & $144(96.0 \%)$ & $-17.1 \pm 3.5$ & $150(100.0 \%)$ & $<0.001$ \\
\hline 10. Mid inferior* & $-22.9 \pm 5.2$ & $138(92.0 \%)$ & $-19.3 \pm 3.7$ & $150(100.0 \%)$ & $<0.001$ \\
\hline 13. Apical anterior* & $-21.5 \pm 7.2$ & $150(100.0 \%)$ & $-15.0 \pm 3.2$ & $150(100.0 \%)$ & $<0.001$ \\
\hline 14. Apical septal* & $-21.5 \pm 4.0$ & $150(100.0 \%)$ & $-16.7 \pm 3.8$ & $150(100.0 \%)$ & $<0.001$ \\
\hline 15. Apical inferior & $-21.0 \pm 6.3$ & $150(100.0 \%)$ & $-20.6 \pm 4.6$ & $150(100.0 \%)$ & 0.464 \\
\hline 16. Apical lateral & $-18.6 \pm 6.5$ & $150(100.0 \%)$ & $-18.9 \pm 3.6$ & $150(100.0 \%)$ & 0.488 \\
\hline
\end{tabular}

$\mathrm{N}(\%)$ means the number (fraction) of segments with available SLS. ${ }^{*} \mathrm{P}<0.05$. CMR-TT, cardiovascular magnetic resonance based tissue tracking; SLS, segmental longitudinal peak strain. 

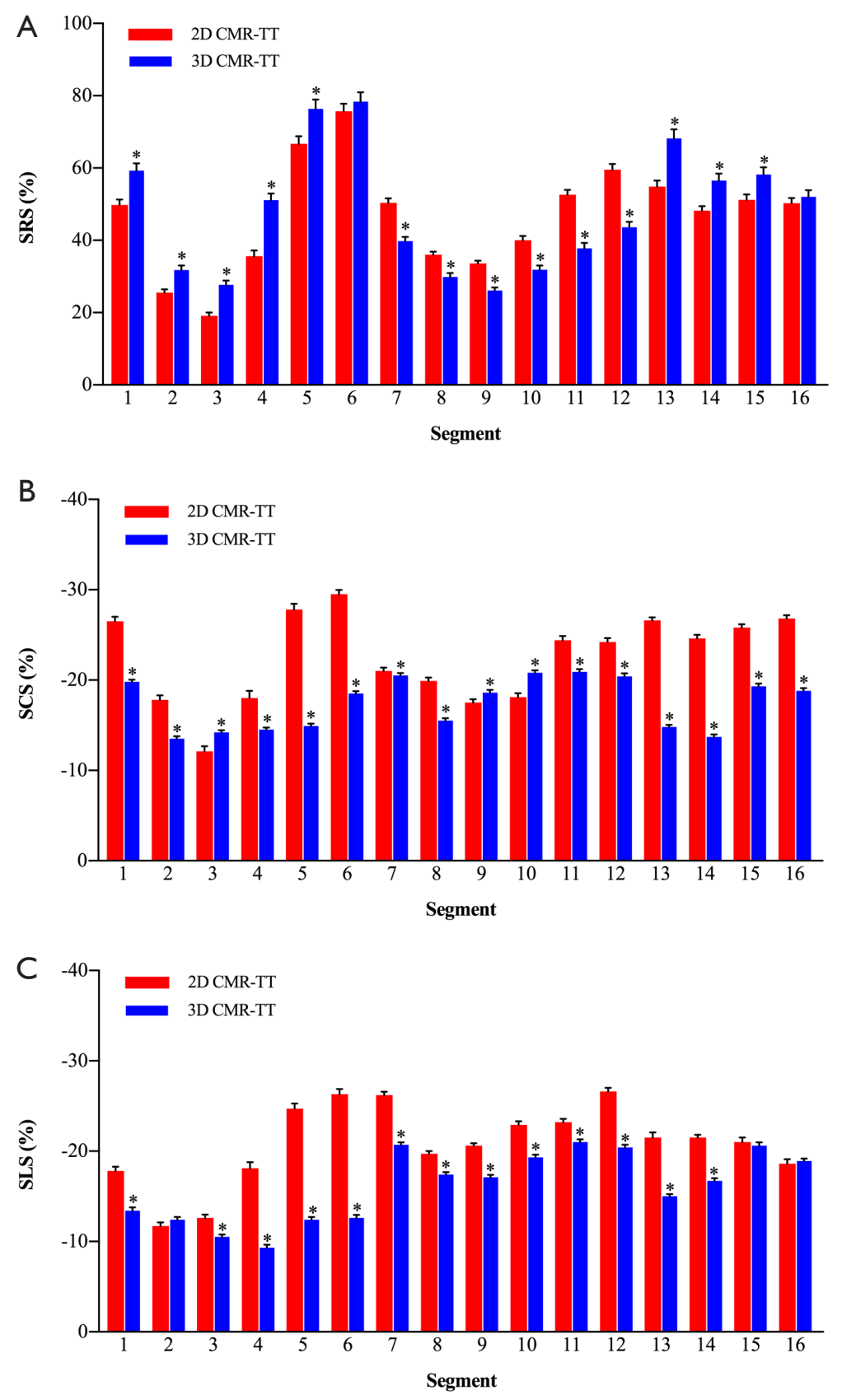

Figure 2 Comparison of LV multi-dimensional segmental peak strains derived from 2D and 3D CMR-TT. (A) SRS. (B) SCS. (C) SLS. This figure provides intuitive expression of reference value and tendency of multi-dimensional strains at each segment in the context of 2D and 3D CMR-TT (red and blue). Segment: 1. basal anterior, 2. basal anteroseptal, 3. basal inferoseptal, 4. basal inferior, 5. basal inferolateral, 6. basal anterolateral, 7. mid anterior, 8. mid anteroseptal, 9. mid inferoseptal, 10. mid inferior, 11. mid inferolateral, 12. mid anterolateral, 13. apical anterior, 14. apical septal, 15. apical inferior, 16. apical lateral. ${ }^{*} \mathrm{P}<0.05$. CMR-TT, cardiovascular magnetic resonance based tissue tracking; LV, left ventricular; SRS, segmental radial peak strain; SCS, segmental circumferential peak strain; SLS, segmental longitudinal peak strain. 
Table 5 Reference values of LV global strains measured with 2D and 3D CMR-TT

\begin{tabular}{|c|c|c|c|}
\hline Variable & 2D CMR-TT & 3D CMR-TT & $P$ value \\
\hline \multicolumn{4}{|l|}{ Global mean strains (\%) } \\
\hline Global radial mean strain (MRS) & $46.8 \pm 9.5$ & $48.0 \pm 13.5$ & 0.644 \\
\hline Global circumferential mean strain (MCS) & $-22.6 \pm 2.9$ & $-17.4 \pm 2.6$ & $<0.001^{*}$ \\
\hline Global longitudinal mean strain (MLS) & $-20.8 \pm 2.2$ & $-16.1 \pm 2.3$ & $<0.001^{*}$ \\
\hline Global radial peak strain (GRS) & $41.7 \pm 9.5^{\#}$ & $44.4 \pm 13.0^{\#}$ & 0.094 \\
\hline Global circumferential peak strain (GCS) & $-22.0 \pm 3.3^{\#}$ & $-17.0 \pm 2.7^{\#}$ & $<0.001^{*}$ \\
\hline Global longitudinal peak strain (GLS) & $-18.6 \pm 2.7^{\#}$ & $-15.4 \pm 2.3^{\#}$ & $<0.001^{*}$ \\
\hline
\end{tabular}

Results are reported as mean $\pm \mathrm{SD}$. *Adjusted $\mathrm{P}<0.05: 2 \mathrm{D}$ vs. 3D; " adjusted $\mathrm{P}<0.05$ : global peak strains vs. global mean strains. CMR-TT, cardiovascular magnetic resonance based tissue tracking.

We also observed that 3D global peak strains were highly correlated with $2 \mathrm{D}$ global mean ( $\mathrm{r}=0.71$ to 0.90$)$ and peak strains ( $\mathrm{r}=0.75$ to 0.89$)$ as well as $3 \mathrm{D}$ global mean strains $(\mathrm{r}=0.99$, all $\mathrm{P}<0.05)$.

\section{Gender- and age-related difference of $L V 3 D$ global peak strains}

Table 6 and Figure 4 illustrate the gender- and age-related difference and reference values of LV 3D global peak strains. In general, females showed larger amplitude of LV global peak strains than males as $47.1 \% \pm 13.4 \%$ vs. $41.7 \% \pm 12.0 \%$ for GRS, $-17.5 \% \pm 2.8 \% v s$. $-16.5 \% \pm 2.5 \%$ for GCS and $-16.0 \% \pm 2.3 \%$ vs. $-14.8 \% \pm 2.2 \%$ for GLS (all $\mathrm{P}<0.05$ ). The gender-related difference got more prominent with aging and significant in $\mathrm{G}_{61-80}$ group. In addition, difference of global peak strains between $\mathrm{G}_{61-80}$ and $\mathrm{G}_{20-40} / \mathrm{G}_{41-60}$ indicates the existence of age-related difference $(\mathrm{P}<0.05)$.

\section{Intra- and inter-observer reproducibility of $2 / 3 D$ CMR-TT}

The intra-observer reproducibility of 2/3D CMR-TT in measuring $\mathrm{LV}$ global and segmental strains was tested and presented in Tables 7 and 8 . At the segmental level, ICC of SRS, SCS and SLS were 0.83-0.99, 0.80-0.98 and 0.72-0.99 for 2D CMR-TT, and 0.87-0.97, 0.86-0.98 and 0.84-0.99 for 3D CMR-TT. Compared with 2D CMRTT, 3D CMR-TT presented higher CoV $(18.59 \% \pm 5.95 \%$ vs. $10.68 \% \pm 3.46 \%, \mathrm{P}<0.001)$ for $\mathrm{SRS}$ and similar $\mathrm{CoV}$ for SCS $(6.88 \% \pm 3.47 \%$ vs. $10.26 \% \pm 6.65 \%, \mathrm{P}=0.10)$ and SLS $(9.79 \% \pm 4.59 \%$ vs. $9.38 \% \pm 4.53 \%, \mathrm{P}=0.80)$. At the global level, 2/3D global mean and peak strains showed high reproducibility (ICC $\geq 0.97$ ) and low variability ( $\mathrm{CoV}$ $\leq 6.31 \%)$. The results of inter-observer reproducibility test presented in Tables 9 and 10 also validated the better reproducibility of CMR-TT in the measurement of LV global deformation.

\section{Discussion}

To the best of our knowledge, this study is the largest one to comprehensively investigate the feasibility and reproducibility of 2/3D CMR-TT for quantifying $\mathrm{LV}$ global and segmental multi-dimensional strains with $\mathrm{CVI}^{42}$ software package. We also established gender- and agerelated reference value of $L V$ global peak strain with $3 \mathrm{D}$ CMR-TT in 150 healthy volunteers without cardiovascular diseases or related risk factors.

\section{CMR-TT}

CMR-TT technique is emerging as an advanced technique contributing to quantifying myocardial mechanical parameters including strain, strain rate, displacement and velocity. Its principle is based on identifying and tracking comparable myocardial features of CMR cine images over the cardiac cycle (11). It has been proven successful in diagnosing a variety of diseases, such as bicuspid aortic valve disease, cardiomyopathy and heart failure with preserved EF $(5,19,20)$. Previous studies have validated the comparable reproducibility of CMR-TT (Circle $\mathrm{CVI}^{42}$ ) with CMR feature tracking (TomTec Arena), even though strain values weren't interchangeable between 

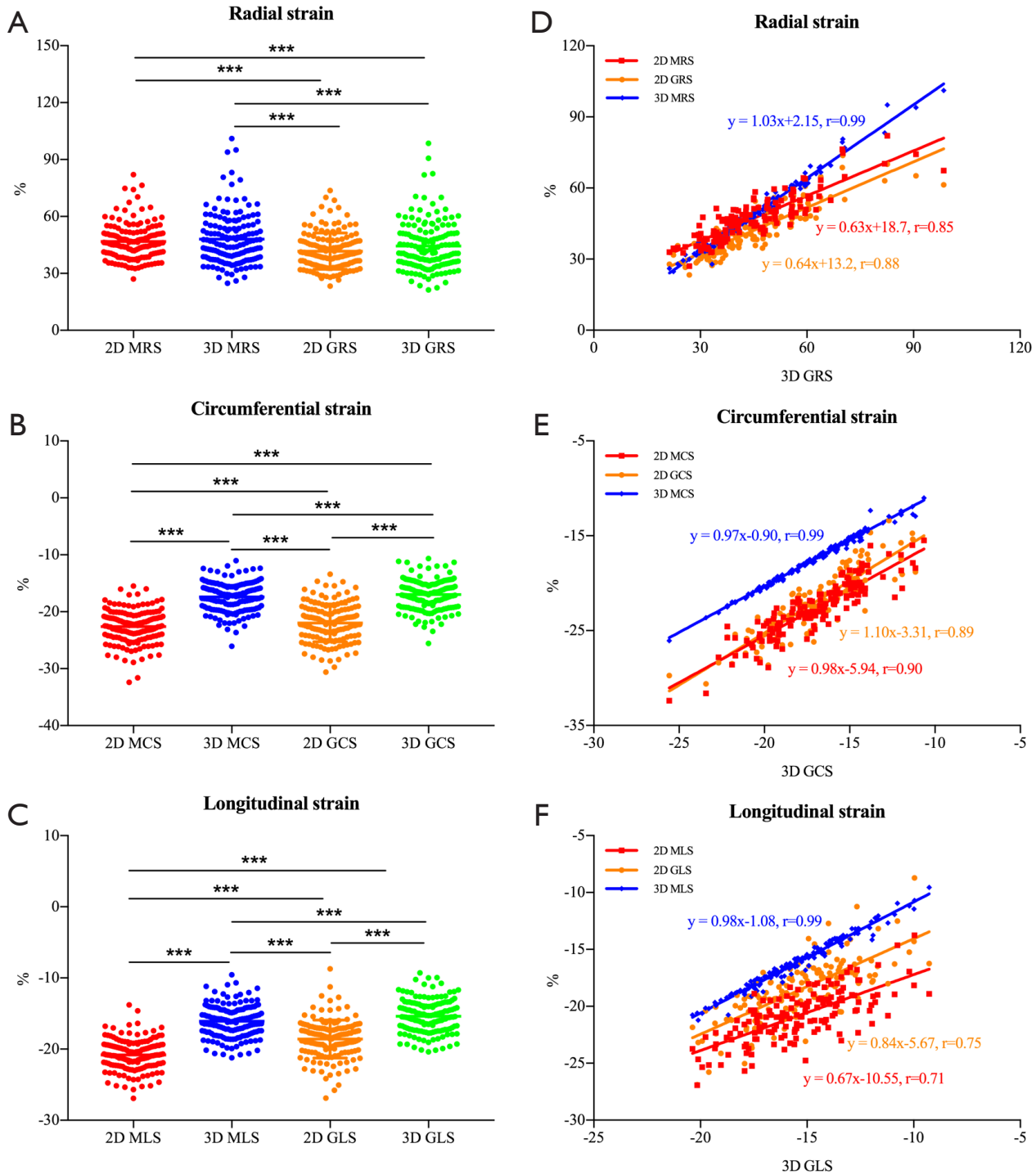

Figure 3 Comparisons and correlations among LV 2/3D global mean and peak strains. These scatter plots represent the data of LV radial, circumferential and longitudinal strains generated by four different calculations. (A-C) Comparisons among LV 2/3D global mean and peak strains. ${ }^{* * *}$ adjusted $\mathrm{P}<0.001$. (D-F) Correlations among LV 2/3D global mean and peak strains. Equations of linear regression and value of correlation coefficient $(r)$ are added beside the corresponding lines $(\mathrm{P}<0.05)$. MRS, global radial mean strain; MCS, global circumferential mean strain; MLS, global longitudinal mean strain; GRS, global radial peak strain; GCS, global circumferential peak strain; GLS, global longitudinal peak strain.

Table 6 Gender- and age-related reference value of LV 3D global peak strains

\begin{tabular}{|c|c|c|c|c|c|c|c|c|c|c|c|}
\hline \multirow{2}{*}{ Variable } & \multicolumn{3}{|c|}{$\mathrm{G}_{20-40}$} & \multicolumn{3}{|c|}{$\mathrm{G}_{41-60}$} & \multicolumn{3}{|c|}{$\mathrm{G}_{61-80}$} & \multirow{2}{*}{$\begin{array}{l}\text { Male } \\
(n=75)\end{array}$} & \multirow{2}{*}{$\begin{array}{c}\text { Female } \\
(n=75)\end{array}$} \\
\hline & Male & Female & All- $\mathrm{G}_{20-40}$ & Male & Female & All- $\mathrm{G}_{41-60}$ & Male & Female & All- $-G_{61-80}$ & & \\
\hline GRS & $41.2 \pm 14.7$ & $41.9 \pm 9.5$ & $41.6 \pm 12.2$ & $40.4 \pm 11.1$ & $47.0 \pm 16.6$ & $43.7 \pm 14.3$ & $43.6 \pm 10.1$ & $52.4 \pm 11.4^{a}$ & $48.0 \pm 11.5^{b}$ & $41.7 \pm 12.0$ & $47.1 \pm 13.4^{a}$ \\
\hline GLS & $-14.9 \pm 1.8$ & $-15.7 \pm 2.3$ & $-15.3 \pm 2.1$ & $-14.3 \pm 2.4$ & $-15.2 \pm 2.6$ & $-14.7 \pm 2.5$ & $-15.1 \pm 2.4$ & $-17.0 \pm 1.8^{a}$ & $-16.1 \pm 2.3^{c}$ & $-14.8 \pm 2.2$ & $-16.0 \pm 2.3^{\mathrm{a}}$ \\
\hline
\end{tabular}

Results are reported as mean $\pm \mathrm{SD}$. All strain values are given in $\%$. ${ }^{\mathrm{a}} \mathrm{P}<0.05$ : male vs. female; ${ }^{\mathrm{b}} \mathrm{P}<0.05: \mathrm{G}_{20-40}$ vs. $\mathrm{G}_{61-80} ;{ }^{\mathrm{c}} \mathrm{P}<0.05: \mathrm{G}_{41-60}$ vs.

$\mathrm{G}_{61-80}$. LV, left ventricular; GRS, global radial peak strain; GCS, global circumferential peak strain; GLS, global longitudinal peak strain. 
A

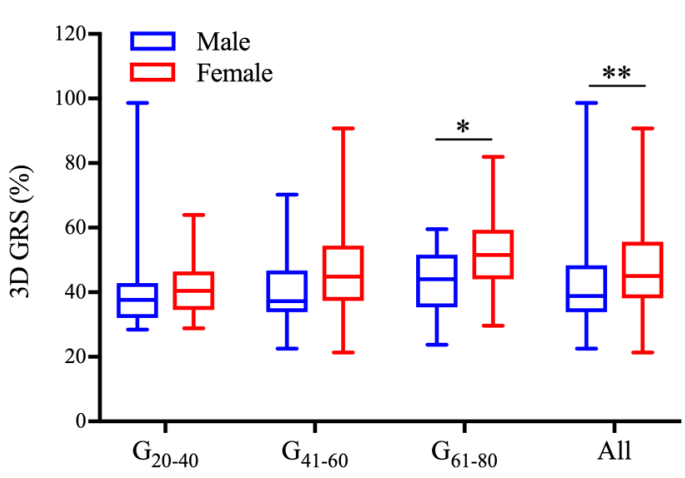

B

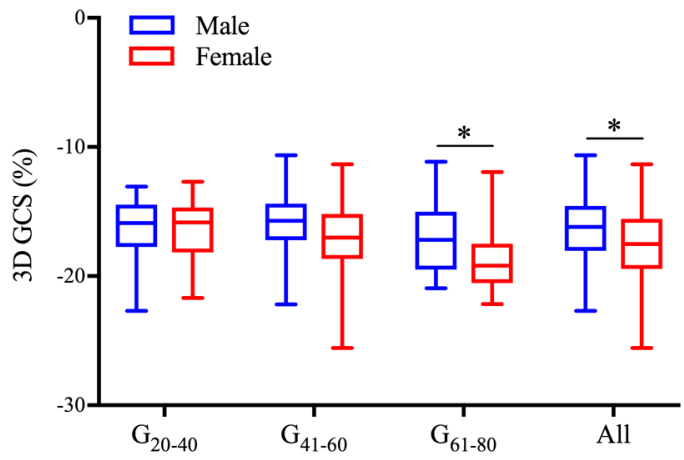

C

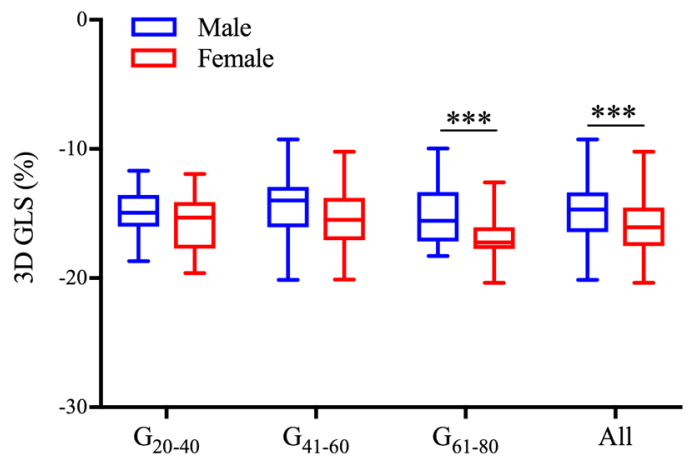

D Age-related difference of 3D GRS

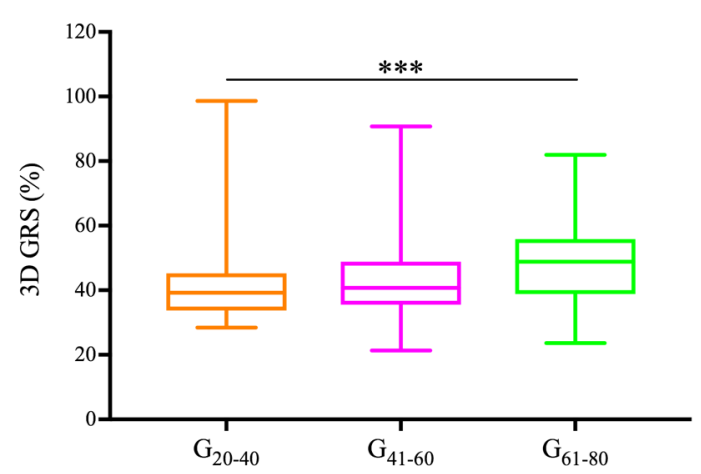

E

Age-related difference of 3D GCS

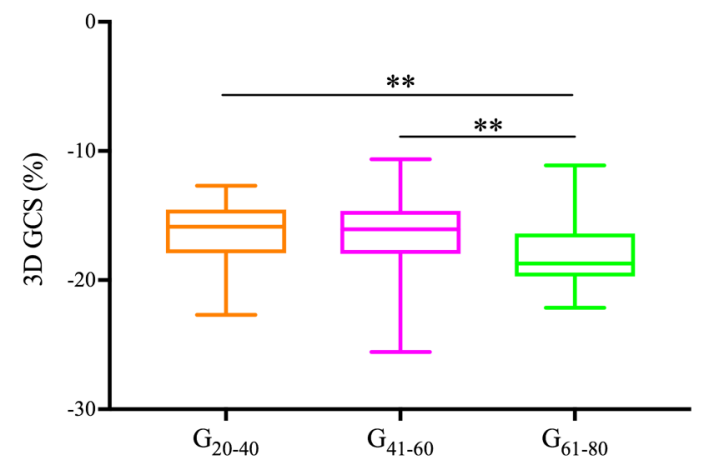

$\mathrm{F}$

Age-related difference of 3D GLS

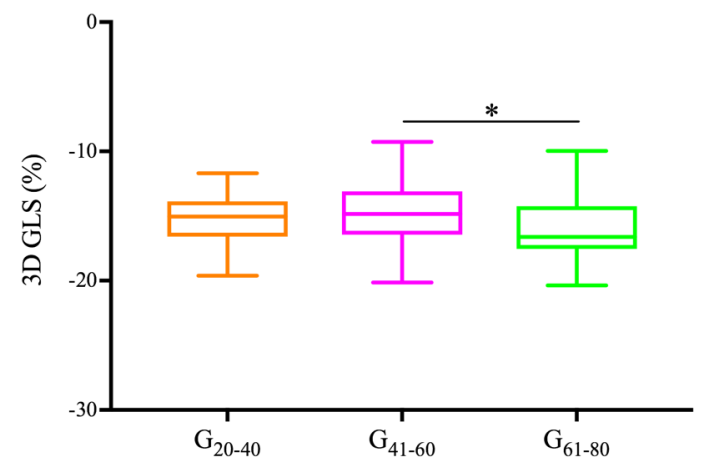

Figure 4 Gender- and age-related difference of LV 3D global peak strains. (A-C) Gender-related difference of GRS, GCS and GLS. (D-F) Age-related difference of GRS, GCS and GLS. The box-and-whisker plots represent the values between lower and upper quartile, and the middle line expresses the median in individual group. The minimum and maximum are shown at the end of whisker after excluding outliers. ${ }^{*} \mathrm{P}<0.05,{ }^{* *} \mathrm{P}<0.01,{ }^{* * *} \mathrm{P}<0.001$. GRS, global radial peak strain; GCS, global circumferential peak strain; GLS, global longitudinal peak strain. 
Table 7 Intra-observer reproducibility of 2D CMR-TT

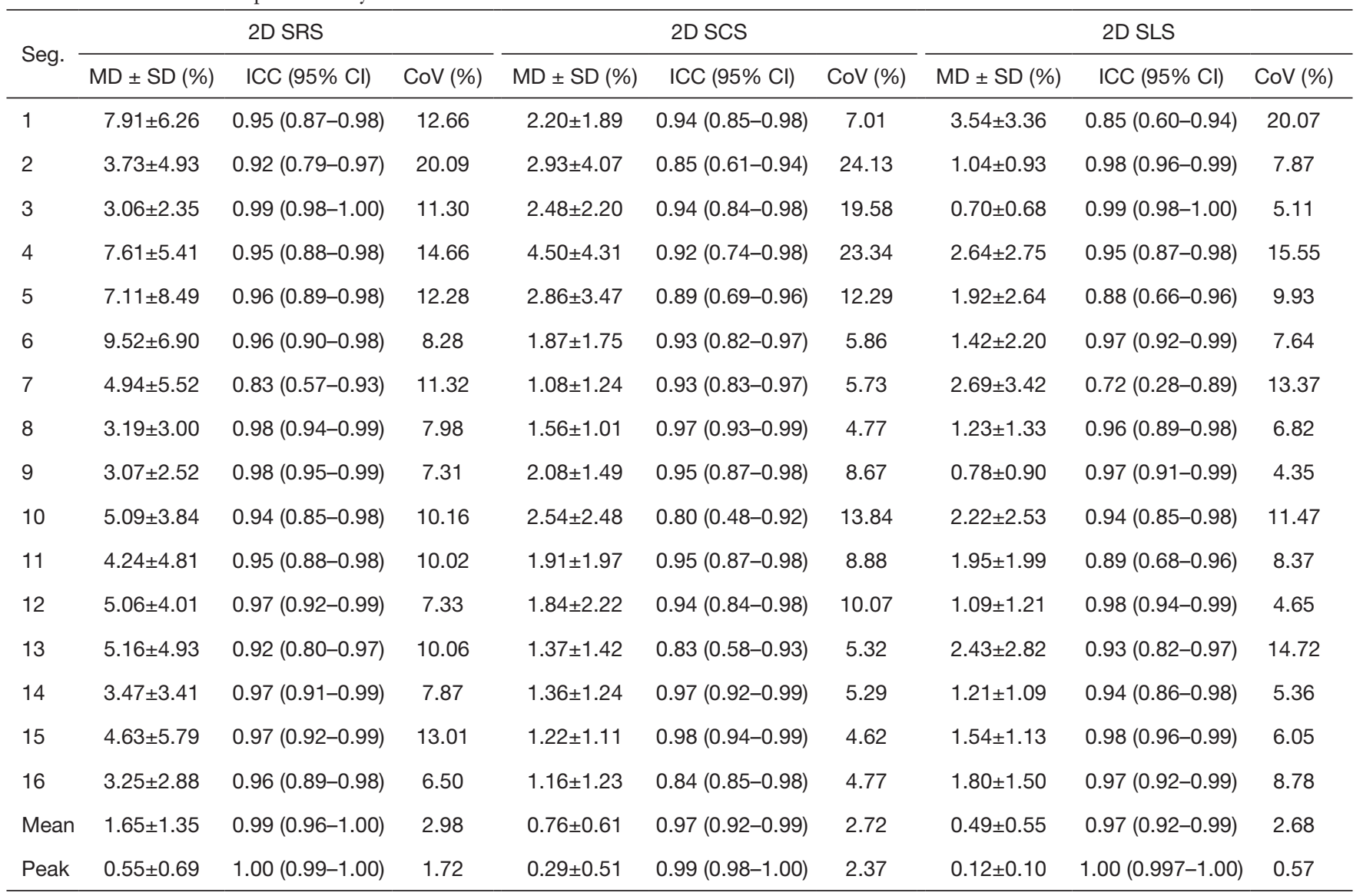

CMR-TT, cardiovascular magnetic resonance based tissue tracking; SRS, segmental radial peak strain; SCS, segmental circumferential peak strain; SLS, segmental longitudinal peak strain; MD, mean difference; SD, standard deviation; ICC, intra-class correlation coefficient; $\mathrm{Cl}$, confidence interval; $\mathrm{CoV}$, coefficient of variation.

vendors $(8,10)$. Cao et al. also observed good agreement between CMR-TT and conventional CMR tagging (21). Since there is no consensus on algorithms chosen for LV myocardial strain assessment and no standardized protocol for further clinical application, feasibility and reproducibility of CMR-TT at $2 \mathrm{D}$ and $3 \mathrm{D}$ level need to be assessed. Liu et al. selectively measured 2D strains at short-axis mid sections or horizontal long-axis images and assessed the reproducibility of $2 / 3 \mathrm{D}$ CMR-TT in measuring global peak strains among 100 subjects (17). In our study, we fully investigated the reference values, correlations and reproducibility of $\mathrm{LV}$ global mean and peak strains, and assessed all segmental strains with $2 / 3 \mathrm{D}$ CMR-TT at radial, circumferential and longitudinal directions among 150 healthy volunteers. Further genderand age-related differences of $3 \mathrm{D}$ global peak strains were evaluated.

\section{Feasibility and reproducibility of 2/3D CMR-TT}

2D CMR-TT could obtain SRS and SCS from a shortaxis stack and acquire SRS and SLS from long-axis cine images by tracking regional tissues over the cardiac cycle. Quantification of circumferential strain in the basal inferior and inferolateral segments was more likely to fail than in any other segments. The observed limitations in basal tracking weakened the application of 2D CMR$\mathrm{TT}$ in assessing regional deformation as in concordance with Maceira's report (20). 3D CMR-TT yielded 100\% success from the base to the apex indicating its superior performance in quantification of segmental strain. The amplitudes of LV segmental strains provided by 3D CMRTT were significantly different (usually smaller) from those by 2D CMR-TT in most segments. Meanwhile, 3D CMR-TT presented worse intra-observer reproducibility 
Table 8 Intra-observer reproducibility of 3D CMR-TT

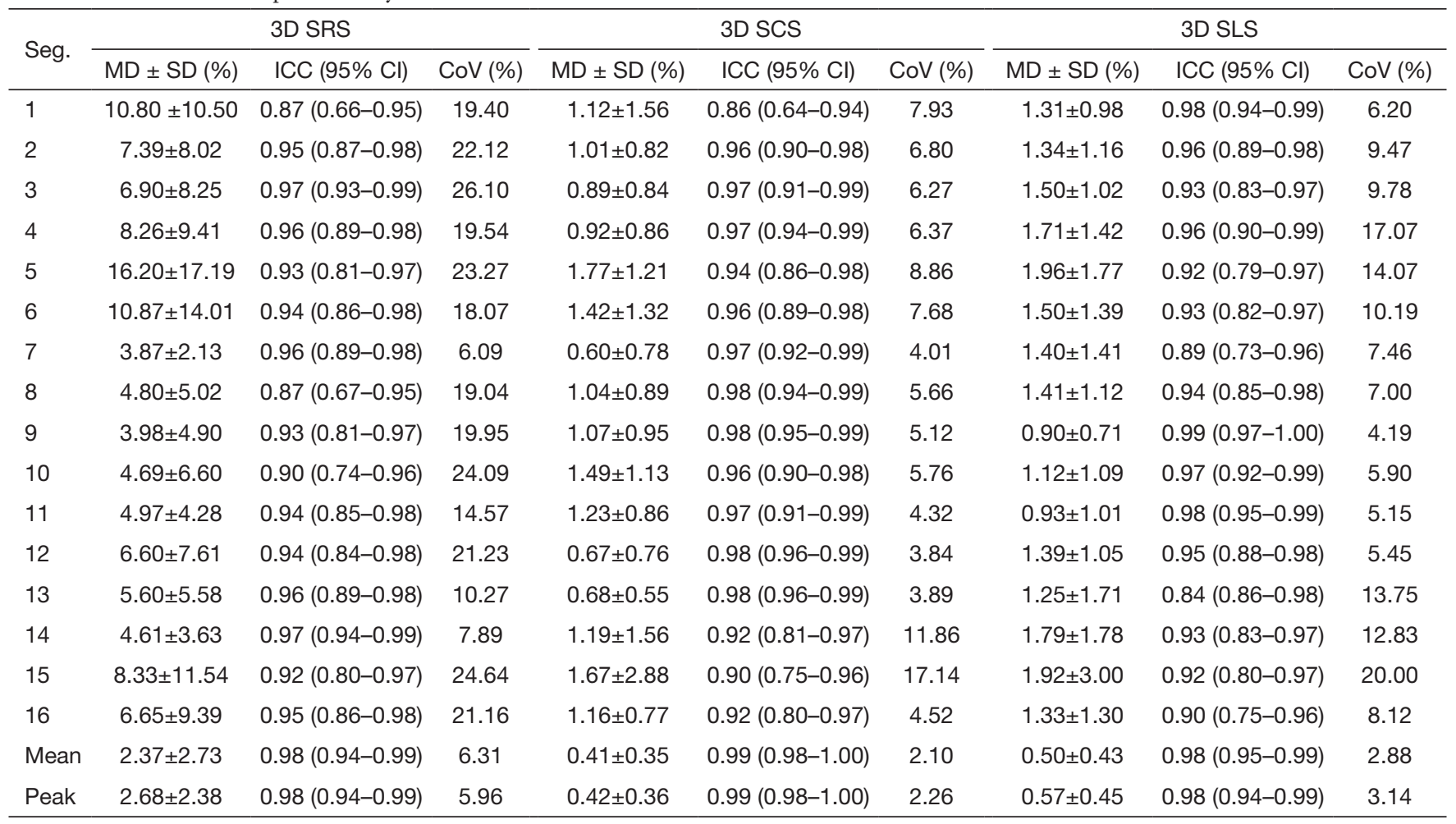

MD, mean difference; SD, standard deviation; ICC, intra-class correlation coefficient; $\mathrm{Cl}$, confidence interval; CoV, coefficient of variation.

Table 9 Inter-observer reproducibility of 2D CMR-TT

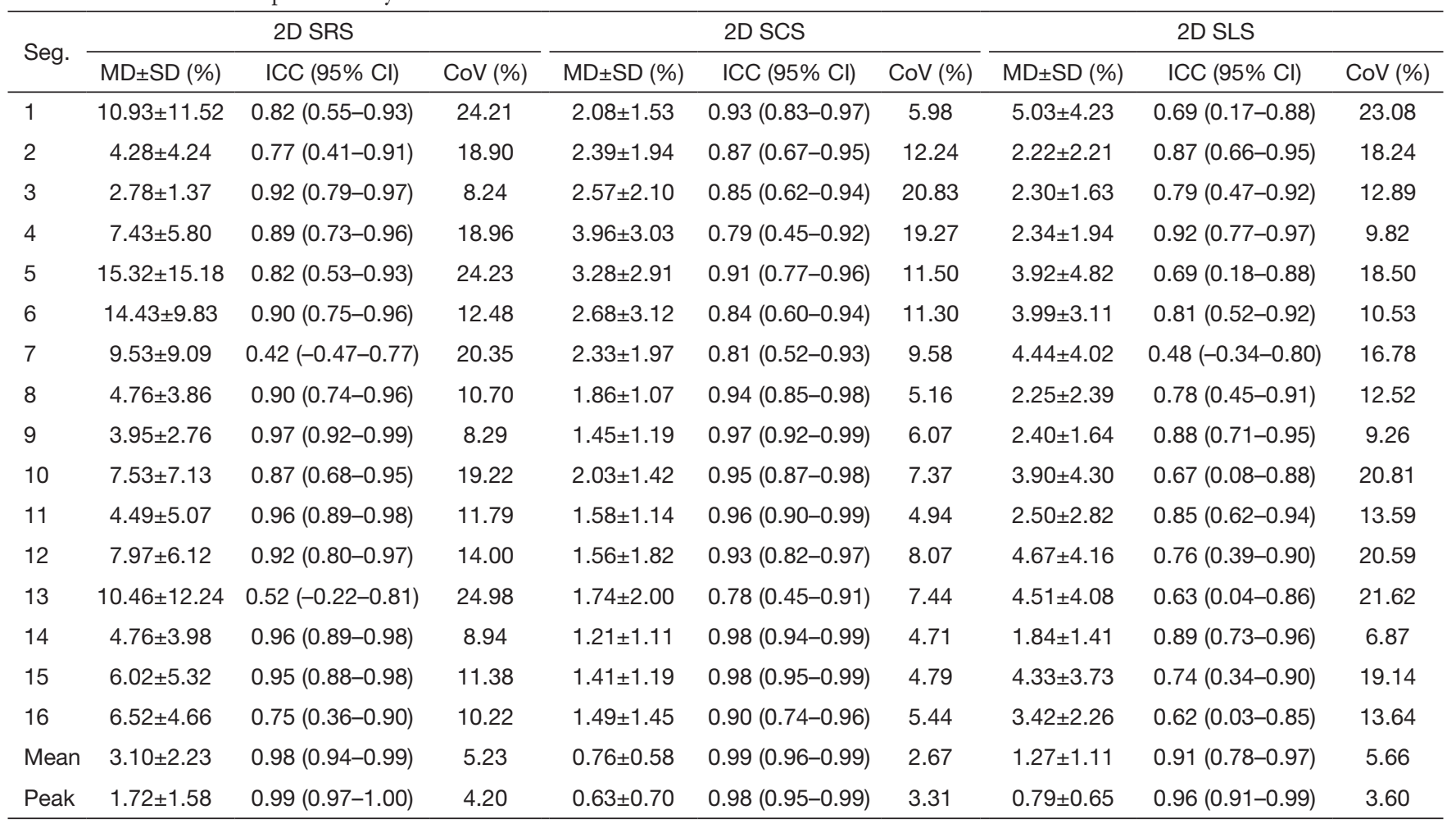

$\mathrm{MD}$, mean difference; SD, standard deviation; ICC, intra-class correlation coefficient; $\mathrm{Cl}$, confidence interval; CoV, coefficient of variation. 
Table 10 Inter-observer reproducibility of 3D CMR-TT

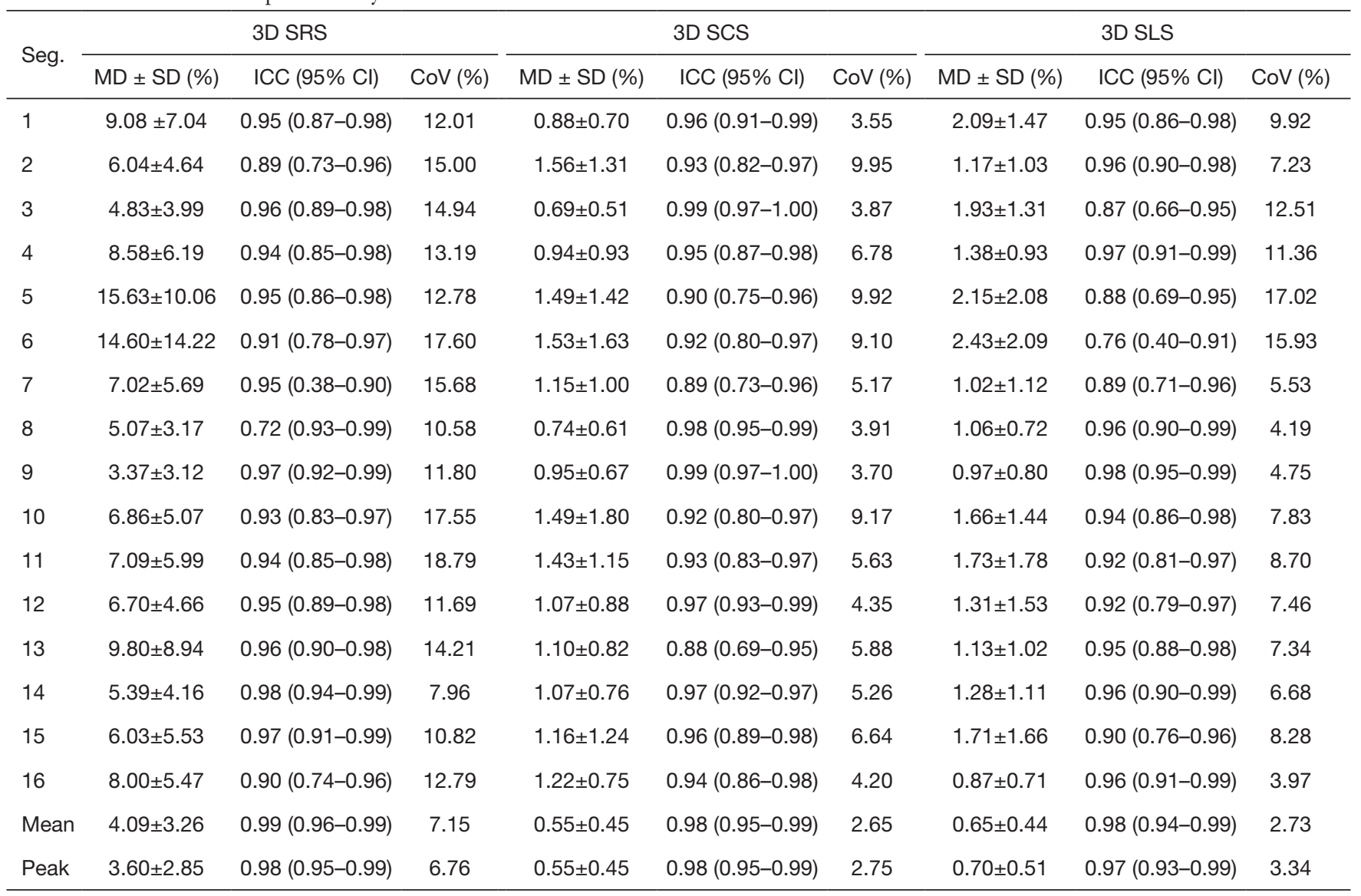

$\mathrm{MD}$, mean difference; SD, standard deviation; ICC, intra-class correlation coefficient; $\mathrm{Cl}$, confidence interval; CoV, coefficient of variation.

in radial, comparable reproducibility in circumferential and longitudinal tracking compared with 2D CMR-TT at segmental level. Hence, we hypothesize that both 2D and 3D CMR-TT techniques can be used to assess LV segmental circumferential and longitudinal strain, while $2 \mathrm{D}$ algorithm may work more stably and reliably than $3 \mathrm{D}$ method in measuring radial segmental strains.

At global level, there was no significant difference between $2 \mathrm{D}$ and $3 \mathrm{D}$ global radial strain values, and 3D global circumferential and longitudinal strains were significantly lower than 2D data. The difference between 2D and 3D modalities may be associated with out-of-plan motion and algorithm-determined geometric assumption $(15,22)$. Both 2D and 3D CMR-TT performed well in measuring all global strains since the intra- and interobserver variability was low $(\mathrm{CoV} \leq 6.31 \%)$.

For feature tracking or tissue tracking, it's a consensus that global tracking is more reliable and preferred than local tracking since it estimates an average process where errors may partly cancel out (10). We found the intra-observer variability of global tracking was much lower than that of segmental approach (CoV: $3.0 \% \pm 1.6 \%$ vs. $10.9 \% \pm 6.0 \%$ ). Considering that $3 \mathrm{D}$ global peak strain was generated automatically, it can be utilized directly and efficiently to evaluate $\mathrm{LV}$ global deformation without additional calculation. Meanwhile, 3D global peak strain was highly correlated with 3D global mean strain and 2D global mean and peak strain, it can reflect $L V$ global deformation on the behalf of all kinds of global strain parameters.

\section{Gender- and age-related difference of strains}

Considering the different LV morphologic features between males and females as well as the young and the old, specific reference values for the different groups are likely required. Actually, gender-related difference of strain is still a matter of debate. Andre et al. found females had more negative GCS and GLS compared with males, 
whereas males had higher GRS (23). However, Taylor et al. found females had similar GRS and GCS along with more negative GLS compared with males (24). In our study, healthy females showed significantly larger absolute values of GRS, GCS and GLS than males, which were positively correlated with EF and inversely correlated with LVMI, LVEDVI and LVESVI (24). Interestingly, we observed that females merely presented significantly larger amplitude of strains in $G_{61-80}$ rather than $G_{20-40}$ or $G_{41-60}$, implying the age-related heterogeneity with respect to gender-related difference. The augmented gender-related difference of strains in the elderly population may be caused by the increasing difference of LVEF, LVEDVI and LVESVI between males and females with ageing. The age-related difference of global peak strains along with $L V$ volume and HR were detected between $G_{20-40}$ and $G_{61-80}$. Therefore, we hypothesize that the larger amplitude of systolic strains of elderly population may be a mechanical compensation for slower HR and myocardial remodeling due to natural aging $(25,26)$.

\section{Limitations}

One limitation of our study is the quality of semiautomated contour delineation and automated tracking of myocardium, which may be more pronounced in case of poor image quality and contour conspicuity. Therefore, we inspected the boundary points visually and corrected the contours manually, which was likely to cause minor subjective bias. However, it's an inevitable procedure and problem of this kind of analysis. Secondly, we didn't compare CMR-TT to other tracking modalities such as tagging and feature tracking, it's far from the aim of our study. However, previous studies have compared CMRTT with CMR tagging and feature tracking, and proved CMR-TT of good reproducibility $(8,10)$. Thirdly, in the context of 3D tracking, LV twisting motion and out-ofplane motion could affect strain assessment compared with 2D algorithms. Moreover, various factors may affect the quantification of strain, including image acquisition, algorithms and even software versions. The reference values provided by our study are software and algorithms specific, they can't be simply applied under other circumstances.

\section{Conclusions}

In conclusion, our study provides detailed insight into the feasibility, reproducibility and reference value of $\mathrm{LV}$ global and segmental strains using 2/3D CMR-TT in a large healthy population. Due to the good feasibility and reproducibility, we believe that CMR-TT is a practical and valuable modality in evaluating $L V$ global and segmental movement. Considering the algorithms used by CMRTT and the characteristics of human beings, it's necessary to propose the establishment and application of specific reference values for separate modalities and subgroups in clinical routine.

\section{Acknowledgments}

We acknowledge the technical support by Circle. Funding: None.

\section{Footnote}

Conflicts of Interest: All authors have completed the ICMJE uniform disclosure form (available at http://dx.doi. org/10.21037/qims-20-635). The authors have no conflicts of interest to declare.

Ethical Statement: The study was approved by the local ethics committee. All subjects supplied written informed consent.

Open Access Statement: This is an Open Access article distributed in accordance with the Creative Commons Attribution-NonCommercial-NoDerivs 4.0 International License (CC BY-NC-ND 4.0), which permits the noncommercial replication and distribution of the article with the strict proviso that no changes or edits are made and the original work is properly cited (including links to both the formal publication through the relevant DOI and the license). See: https://creativecommons.org/licenses/by-nc-nd/4.0/.

\section{References}

1. Wang H, Amini AA. Cardiac motion and deformation recovery from MRI: a review. IEEE Trans Med Imaging 2012;31:487-503.

2. Klinke V, Muzzarelli S, Lauriers N, Locca D, Vincenti G, Monney P, Lu C, Nothnagel D, Pilz G, Lombardi M, van Rossum AC, Wagner A, Bruder O, Mahrholdt H, Schwitter J. Quality assessment of cardiovascular magnetic resonance in the setting of the European CMR registry: description and validation of standardized criteria. J Cardiovasc Magn Reson 2013;15:55. 
3. Schulz-Menger J, Bluemke DA, Bremerich J, Flamm SD, Fogel MA, Friedrich MG, Kim RJ, von KnobelsdorffBrenkenhoff F, Kramer CM, Pennell DJ, Plein S, Nagel E. Standardized image interpretation and post processing in cardiovascular magnetic resonance: Society for Cardiovascular Magnetic Resonance (SCMR) board of trustees task force on standardized post processing. J Cardiovasc Magn Reson 2013;15:35.

4. Simpson RM, Keegan J, Firmin DN. MR assessment of regional myocardial mechanics. J Magn Reson Imaging 2013;37:576-99.

5. Claus P, Omar AMS, Pedrizzetti G, Sengupta PP, Nagel E. Tissue Tracking Technology for Assessing Cardiac Mechanics: Principles, Normal Values, and Clinical Applications. JACC Cardiovasc Imaging 2015;8:1444-60.

6. Medvedofsky D, Maffessanti F, Weinert L, Tehrani DM, Narang A, Addetia K, Mediratta A, Besser SA, Maor E, Patel AR, Spencer KT, Mor-Avi V, Lang RM. 2D and 3D Echocardiography-Derived Indices of Left Ventricular Function and Shape: Relationship With Mortality. JACC Cardiovasc Imaging 2018;11:1569-79.

7. Nagata $Y$, Takeuchi $M$, Wu VCC, Izumo M, Suzuki K, Sato K, Seo Y, Akashi YJ, Aonuma K, Otsuji Y. Prognostic Value of LV Deformation Parameters Using 2D and 3D SpeckleTracking Echocardiography in Asymptomatic Patients With Severe Aortic Stenosis and Preserved LV Ejection Fraction. JACC Cardiovasc Imaging 2015;8:235-45.

8. Barreiro-Perez M, Curione D, Symons R, Claus P, Voigt JU, Bogaert J. Left ventricular global myocardial strain assessment comparing the reproducibility of four commercially available CMR-feature tracking algorithms. Eur Radiol 2018;28:5137-47.

9. Petersen SE, Jung BA, Wiesmann F, Selvanayagam JB, Francis JM, Hennig J, Neubauer S, Robson MD. Myocardial tissue phase mapping with cine phase-contrast MR imaging: Regional wall motion analysis in healthy volunteers. Radiology 2006;238:816-26.

10. Schuster A, Stahnke VC, Unterberg-Buchwald C, Kowallick JT, Lamata P, Steinmetz M, Kutty S, Fasshauer M, Staab W, Sohns JM, Bigalke B, Ritter C, Hasenfuss G, Beerbaum P, Lotz J. Cardiovascular magnetic resonance feature-tracking assessment of myocardial mechanics: Intervendor agreement and considerations regarding reproducibility. Clin Radiol 2015;70:989-98.

11. Pedrizzetti G, Claus P, Kilner PJ, Nagel E. Principles of cardiovascular magnetic resonance feature tracking and echocardiographic speckle tracking for informed clinical use. J Cardiovasc Magn Reson 2016;18:51.
12. Kowallick JT, Kutty S, Edelmann F, Chiribiri A, Villa A, Steinmetz M, Sohns JM, Staab W, Bettencourt N, Unterberg-Buchwald C, Hasenfuss G, Lotz J, Schuster A. Quantification of left atrial strain and strain rate using Cardiovascular Magnetic Resonance myocardial feature tracking: a feasibility study. J Cardiovasc Magn Reson 2014;16:60.

13. Hwang JW, Kim SM, Park SJ, Cho EJ, Kim EK, Chang SA, Lee SC, Choe YH, Park SW. Assessment of reverse remodeling predicted by myocardial deformation on tissue tracking in patients with severe aortic stenosis: a cardiovascular magnetic resonance imaging study. J Cardiovasc Magn Reson 2017;19:80.

14. Muser D, Tioni C, Shah R, Selvanayagam JB, Nucifora G. Prevalence, Correlates, and Prognostic Relevance of Myocardial Mechanical Dispersion as Assessed by FeatureTracking Cardiac Magnetic Resonance After a First STSegment Elevation Myocardial Infarction. Am J Cardiol 2017;120:527-33.

15. Mochizuki A, Yuda S, Oi Y, Kawamukai M, Nishida J, Kouzu H, Muranaka A, Kokubu N, Shimoshige S, Hashimoto A, Tsuchihashi K, Watanabe N, Miura T. Assessment of left atrial deformation and synchrony by three-dimensional speckle-tracking echocardiography: comparative studies in healthy subjects and patients with atrial fibrillation. J Am Soc Echocardiogr 2013;26:165-74.

16. Cerqueira MD, Weissman NJ, Dilsizian V, Jacobs AK, Kaul S, Laskey WK, Pennell DJ, Rumberger JA, Ryan R, Verani MS, Myoc AHAWG. Standardized myocardial segmentation and nomenclature for tomographic Imaging of the heart - A statement for healthcare professionals from the Cardiac Imaging Committee of the Council on Clinical Cardiology of the American Heart Association. Int J Cardiovasc Imaging 2002;18:539-42.

17. Liu B, Dardeer AM, Moody WE, Hayer MK, Baig S, Price AM, Leyva F, Edwards NC, Steeds RP. Reference ranges for three-dimensional feature tracking cardiac magnetic resonance: comparison with two-dimensional methodology and relevance of age and gender. Int J Cardiovasc Imaging 2018;34:761-75.

18. Hu LW, Wang Q, Gregory BP, Ouyang RZ, Sun AM, Guo C, Han TT, Zhong YM. Quantitative comparison of twodimensional and three-dimensional strain measurement using MRI feature tracking in repair Fontan patients and normal child volunteers. BMC Medical Imaging 2020;20:8.

19. Nucifora G, Miller J, Gillebert C, Shah R, Perry R, Raven C, Joseph MX, Selvanayagam JB. Ascending Aorta and Myocardial Mechanics in Patients with 
"Clinically Normal" Bicuspid Aortic Valve Insights from Cardiovascular Magnetic Resonance Tissue-Tracking Imaging. Int Heart J 2018;59:741-9.

20. Maceira AM, Tuset-Sanchis L, Lopez-Garrido M, San Andres M, Lopez-Lereu MP, Monmeneu JV, GarciaGonzalez MP, Higueras L. Feasibility and reproducibility of feature-tracking-based strain and strain rate measures of the left ventricle in different diseases and genders. J Magn Reson Imaging 2018;47:1415-25.

21. Cao JJ, Ngai N, Duncanson L, Cheng J, Gliganic K, Chen QZ. A comparison of both DENSE and feature tracking techniques with tagging for the cardiovascular magnetic resonance assessment of myocardial strain. J Cardiovasc Magn Reson 2018;20:26.

22. Berganza FM, de Alba CG, Ozcelik N, Adebo D. Cardiac Magnetic Resonance Feature Tracking Biventricular TwoDimensional and Three-Dimensional Strains to Evaluate Ventricular Function in Children After Repaired Tetralogy of Fallot as Compared with Healthy Children. Pediatr Cardiol 2017;38:566-74.

23. Andre F, Steen H, Matheis P, Westkott M, Breuninger

Cite this article as: Qu YY, Paul J, Li H, Ma GS, Buckert D, Rasche V. Left ventricular myocardial strain quantification with two- and three-dimensional cardiovascular magnetic resonance based tissue tracking. Quant Imaging Med Surg 2021;11(4):14211436. doi: 10.21037/qims-20-635
K, Sander Y, Kammerer R, Galuschky C, Giannitsis E, Korosoglou G, Katus HA, Buss SJ. Age- and genderrelated normal left ventricular deformation assessed by cardiovascular magnetic resonance feature tracking. J Cardiovasc Magn Reson 2015;17:25.

24. Taylor RJ, Moody WE, Umar F, Edwards NC, Taylor TJ, Stegemann B, Townend JN, Hor KN, Steeds RP, Mazur W, Leyva F. Myocardial strain measurement with featuretracking cardiovascular magnetic resonance: normal values. Eur Heart J Cardiovasc Imaging 2015;16:871-81.

25. Hung CL, Goncalves A, Shah AM, Cheng S, Kitzman D, Solomon SD. Age- and Sex-Related Influences on Left Ventricular Mechanics in Elderly Individuals Free of Prevalent Heart Failure: The ARIC Study (Atherosclerosis Risk in Communities). Circ Cardiovasc Imaging 2017;10:e004510.

26. Cheng S, Fernandes VRS, Bluemke DA, McClelland RL, Kronmal RA, Lima JAC. Age-Related Left Ventricular Remodeling and Associated Risk for Cardiovascular Outcomes The Multi-Ethnic Study of Atherosclerosis. Circ Cardiovasc Imaging 2009;2:191-8. 